\title{
Electroosmotic flow hysteresis for dissimilar ionic solutions
}

\author{
An Eng Lim, Chun Yee Lim, and Yee Cheong Lam \\ School of Mechanical and Aerospace Engineering, Nanyang Technological University, \\ Nanyang Avenue 50, Singapore 639798
}

(Received 16 March 2015; accepted 1 April 2015; published online 9 April 2015)

\begin{abstract}
Electroosmotic flow (EOF) with two or more fluids is commonly encountered in various microfluidics applications. However, no investigation has hitherto been conducted to investigate the hysteretic or flow direction-dependent behavior during the displacement flow of solutions with dissimilar ionic species. In this investigation, electroosmotic displacement flow involving dissimilar ionic solutions was studied experimentally through a current monitoring method and numerically through finite element simulations. The flow hysteresis can be characterized by the turning and displacement times; turning time refers to the abrupt gradient change of current-time curve while displacement time is the time for one solution to completely displace the other solution. Both experimental and simulation results illustrate that the turning and displacement times for a particular solution pair can be directional-dependent, indicating that the flow conditions in the microchannel are not the same in the two different flow directions. The mechanics of EOF hysteresis was elucidated through the theoretical model which includes the ionic mobility of each species, a major governing parameter. Two distinct mechanics have been identified as the causes for the EOF hysteresis involving dissimilar ionic solutions: the widening/sharpening effect of interfacial region between the two solutions and the difference in ion concentration distributions (and thus average zeta potentials) in different flow directions. The outcome of this investigation contributes to the fundamental understanding of flow behavior in microfluidic systems involving solution pair with dissimilar ionic species. (c) 2015 AIP Publishing LLC. [http://dx.doi.org/10.1063/1.4917386]
\end{abstract}

\section{INTRODUCTION}

Electroosmotic flow (EOF) is induced by electrokinetic phenomenon, whereby surface charge is developed when a solid is placed in contact with a fluid. The surface charge repels co-ions and attracts counter-ions in the fluid to form an electrical double layer (EDL), thus resulting in a thin (nanometer thickness) fluid region with net charge in close proximity to the solid. Common materials employed for fabrication of microfluidic channel such as glass or polydimethylsiloxane (PDMS) typically develop a negative surface charge upon contact with ionic aqueous solutions. This negative surface charge attracts positive ions in the solution and form a net positive charge EDL. An external electric field parallel to the microchannel can be applied to drive the ions in the EDL in the direction of the electric field, inducing the bulk movement of the fluid.

EOF has been employed for various applications in microfluidics, including mixing of analytes, ${ }^{1,2}$ pumping of fluid, ${ }^{3,4}$ separation of particles ${ }^{5} /$ chemical species, $^{6}$ sample trapping, ${ }^{7}$ and pre-concentration. ${ }^{8,9}$ In many of these practical applications, two or more types of fluids with different properties are often involved, with one displacing another. This process of a fluid displacing another fluid is referred to as displacement flow; examples are displacement flows in current monitoring method for zeta potential measurement and field amplified sample stacking (FASS). 
FASS is one of the simplest forms of pre-concentration technique in microfluidic devices. ${ }^{10}$ The concept of FASS involves the setting up of an electric field across two solutions with different conductivities. Charged analytes are stacked at the conductivity boundary when the analytes attempt to traverse from the lower conductivity sample to a higher conductivity background electrolyte (BGE). Extensive review on the recent development of FASS and its applications can be found in the literature. ${ }^{10,11}$

EOF occurs naturally during FASS as the electric field applied to stack or separate the ions would also drive the fluid movement. However, due to the mismatch in EOF velocity in the high and low conductivity solutions, an internal pressure gradient is generated, causing unwanted sample dispersion. The resultant frustrated flow profile is a superposition of a pluglike profile of EOF and a parabolic profile of pressure driven flow. ${ }^{12,13}$ To reduce sample dispersion, EOF is typically suppressed or reduced with application of coating to the microchannel ${ }^{14}$ or additive to the BGE. ${ }^{15}$ In contrast, there are methodologies which exploit EOF to achieve the desired ion pre-concentration and transport effect ${ }^{16-18}$ in a micro/nanofluidic channel.

The current monitoring technique is a common method for measuring zeta potential employing displacement flow involving two solutions with a small difference in concentration, typically $5 \% .{ }^{19}$ When a solution is displacing another with a lower or higher concentration initially residing in the microchannel, the electrical resistance across the channel changes. The resultant electrical current change can be captured by an ammeter during the displacement flow. When the solution has fully displaced the other solution, the current reaches a steady value because the resistance in the microchannel is now constant. By monitoring the current changes in real time, the time for the current to reach a steady value (i.e., the displacement time) can be determined. The zeta potential can then be calculated through the displacement time with the Smoluchowski slip velocity equation. It is a common practice to employ displacement flow of solutions with small $(5 \%-7.5 \%)$ concentration difference; this practice has been adapted and improved by other researchers ${ }^{20-23}$ to measure the zeta potential of a microchannel.

Theoretical studies on the electroosmotic displacement flow of two or three solutions have been conducted by Tang et al. ${ }^{24}$ The interface velocity and current response have been derived for a range of conductivity ratios between the solutions. However, each solution is assumed to consist of similar electrolyte with identical ionic mobilities. The displacement flow involving solution pairs with dissimilar ionic species has not been explored in their theoretical studies.

Similarly, Ren et al. ${ }^{25,26}$ have adopted the electrical circuit model in their investigations of two-fluid electroosmotic displacement flow whereby each fluid is represented by a resistance based on their conductivities. The underlying assumption for the model is that the two solutions must contain similar ionic species, albeit at different concentrations. The ionic mobility of each species in the solution was not taken into account, and hence, flow hysteresis cannot be predicted by the simplified electrical circuit model.

Ren et al. ${ }^{25,26}$ have conducted displacement flow experiments with $0.1 \mathrm{mM}$ lanthanum chloride $\left(\mathrm{LaCl}_{3}\right)$ solution and $0.1 \mathrm{mM}$ potassium chloride $(\mathrm{KCl})$ solution (solution pair with different ion species type) in two different flow directions. However, the displacement times for the flow in the forward and reverse flow directions were not reported. Hence, the displacement time difference, the precursor for the exhibition of the hysteresis effect, was not examined. Therefore, the existence of flow hysteresis could not be detected.

Mampallil et al $^{27}$ have proposed a technique to measure the surface charge of a microchannel based on electroosmotic displacement flow of two solutions with different concentrations. The zeta potentials of the two solutions and the surface charge were obtained by fitting the current-time curve (obtained from the current monitoring experiment) to a theoretical expression. The theoretical expression was derived based on the assumption that the two fluids are having the same electrolyte with different concentrations. Furthermore, the displacement flow was conducted by displacing a lower concentration solution with a higher concentration one; the flow in the reverse direction has not been conducted/reported.

Displacement flow of two ionic solutions with different concentrations has been investigated by our group through the current monitoring method. ${ }^{28}$ It has been experimentally 
demonstrated that the response of the system exhibits a hysteretic behavior, whereby the time for one solution to fully displace the other initially residing in the channel differs depending on the direction of flow. ${ }^{28}$ For example, the displacement time for $1 \mathrm{mM} \mathrm{KCl}$ solution displacing $0.2 \mathrm{mM} \mathrm{KCl}$ in glass micro-capillary is $28 \%$ faster than the flow of $0.2 \mathrm{mM} \mathrm{KCl}$ displacing $1 \mathrm{mM} \mathrm{KCl}$. Similar hysteresis effect has also been observed in PDMS microchannel as well. However, our previous investigation only focused on the displacement flow of solution pair with similar ion species.

This investigation demonstrates for the first time the hysteretic behavior in electroosmotic displacement flow involving solution pair with dissimilar ionic species. In microfluidic applications such as FASS, the electric field is typically applied in one direction throughout the whole investigation. The electric field in ion pre-concentration techniques is directed in the direction which favors the accumulation of the desired species at the two-fluid interface. Despite the abundance of investigations involving displacement flow with dissimilar solutions, no investigation has hitherto been conducted on the comparison of flow behavior when the electric field or displacement flow direction is reversed. Experimental and numerical studies on EOF hysteresis involving dissimilar ionic solutions have been conducted in this investigation. A proper understanding of the hysteretic behavior in electroosmotic displacement flow is important for simulation and prediction of flow behavior in various microfluidic applications.

\section{METHODS AND MATERIALS}

\section{A. Materials and equipment}

Three types of ionic solutions at various concentrations were prepared for the experiments (see Table I). The stock solutions for $1 \mathrm{mM}$ of potassium chloride $(\mathrm{KCl})$, sodium chloride $(\mathrm{NaCl})$, and calcium chloride $\left(\mathrm{CaCl}_{2}\right)$ were prepared by dissolving the salts $(\mathrm{KCl}$ salt from Fluka and the rest from Sigma-Aldrich) in deionized (DI) water. Subsequently, the stock solutions were diluted to solutions of $0.475 \mathrm{mM}(95 \%$ of $0.5 \mathrm{mM})$ and $0.5 \mathrm{mM}$. The solutions properties, such as conductivity and $\mathrm{pH}$, were measured with a conductivity meter (IONCheck 65, Radiometer Analytical) and $\mathrm{pH}$ meter (AccumetAR20, Fisher Scientific). The measured average $\mathrm{pH}$ for all solutions was 5.5. Table I presents the measured conductivities for the solutions.

The microchannel employed was polyimide coated fused silica microcapillary (Polymicro Technologies) with a nominal internal diameter of $100 \mu \mathrm{m}$. Microcapillaries with length of $8 \mathrm{~cm}$ were measured and cut with Shortix Column Cutter (SGT Ltd). The capillary was inserted between two Teflon reservoirs with both diameter and depth of $2 \mathrm{~cm}$. The reservoirs were sufficiently large to ensure negligible liquid level changes during the experiment; this minimizes the back pressure generated due to the difference of liquid level in the reservoirs. ${ }^{29}$ In microfluidic devices with small reservoir, electrolysis at the electrodes might induce local $\mathrm{pH}$ change (due to the production of $\mathrm{H}^{+}$and $\mathrm{OH}^{-}$ions) in unbuffered solutions which can affect the EOF behavior. ${ }^{30}$ Employing large-volume reservoirs can minimize this effect as the concentrations of $\mathrm{H}^{+}$ and $\mathrm{OH}^{-}$ions are diluted significantly in large reservoirs. The electrodes were also placed far from the inlet of the microcapillary to further reduce the $\mathrm{pH}$ change in the microchannel. ${ }^{20}$

TABLE I. Measured solution conductivities.

\begin{tabular}{lc}
\hline \hline Solution & Conductivity $\left(\mu \mathrm{S} \cdot \mathrm{cm}^{-1}\right)$ \\
\hline $0.475 \mathrm{mM} \mathrm{KCl}$ & 70.0 \\
$0.5 \mathrm{mM} \mathrm{KCl}$ & 75.5 \\
$0.475 \mathrm{mM} \mathrm{NaCl}$ & 60.4 \\
$0.5 \mathrm{mM} \mathrm{NaCl}$ & 63.8 \\
$0.475 \mathrm{mM} \mathrm{CaCl}_{2}$ & 129.1 \\
$0.5 \mathrm{mM} \mathrm{CaCl}_{2}$ & 136.7 \\
\hline \hline
\end{tabular}


Fig. 1 shows the schematic diagram of the experiment setup for the current monitoring method for measuring zeta potential and for studying the flow behavior during two-fluid displacement flow. The electric field for inducing EOF was supplied by a high voltage power supply (CZE1000R, Spellman). The current across the microchannel was monitored by connecting a picoammeter (Keithley 6458) in series to the microcapillary. A Labview program was written to control the two devices and record the voltage and current readings through a data acquisition card (PCI-6052E, National Instrument).

\section{B. Experimental methods}

\section{Zeta potential and surface charge density measurements}

Zeta potential and surface charge densities are important parameters which characterize the flow velocity and direction of EOF in a microchannel. The zeta potentials and surface charge densities for $0.5 \mathrm{mM}$ of $\mathrm{KCl}, \mathrm{NaCl}$, and $\mathrm{CaCl}_{2}$ were measured by the current monitoring technique. The time for the current to reach a steady value, i.e., the displacement time, was determined from the current-time curve. The average electroosmotic velocity can then be found by dividing the length of the channel with the displacement time. The formula for the electroosmotic velocity, also known as the Helmholtz-Smoluchowski equation, is given as

$$
v_{e o}=\frac{-\varepsilon_{r} \varepsilon_{0} E \zeta}{\mu},
$$

where $\varepsilon_{r}$ is the dielectric constant of the fluid, $\varepsilon_{o}$ is the permittivity of free space, $E$ is the electric field, $\zeta$ is the zeta potential, and $\mu$ is the dynamic viscosity of the fluid. The zeta potential is then obtained by substituting the average electroosmotic velocity into Eq. (1), and it can be expressed as

$$
\zeta=\frac{-\mu}{\varepsilon_{r} \varepsilon_{0} E} \cdot \frac{L}{t}
$$

where $L$ is the length of the microchannel and $t$ is the displacement time.

In two-fluid displacement flow, the ion distributions in the EDL are disturbed. This causes the local zeta potential along the microchannel to vary according to the local ion distributions. To capture this phenomenon, a constant surface charge was assumed on the channel wall, instead of constant zeta potential, to allow the variation of the zeta potential according to the local net charge density in our numerical simulation (refer to Sec. IV). The relation between the surface charge density and the zeta potential for a general electrolyte is given by the Grahame equation $^{31}$

$$
\sigma_{s}(\zeta)=\operatorname{sgn}(\zeta)\left[2 N_{a} \varepsilon_{o} \varepsilon_{r} k_{b} T \sum c_{o(i)}\left\{\exp \left(\frac{-z_{i} e \zeta}{k_{b} T}\right)-1\right\}\right]^{\frac{1}{2}}
$$

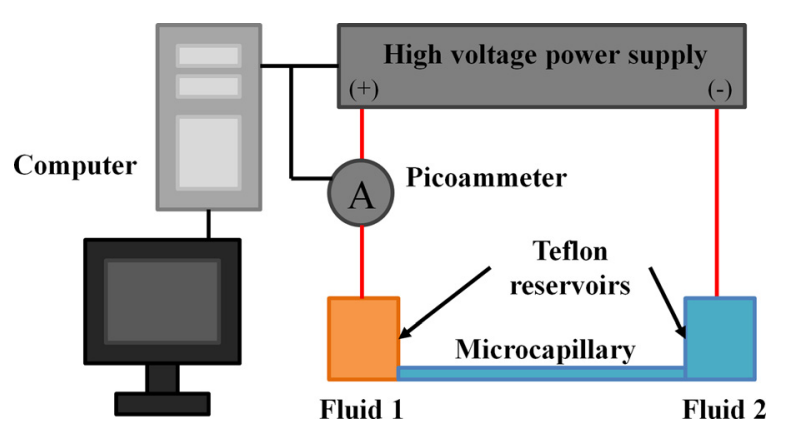

FIG. 1. Schematic diagram of experimental setup for the current monitoring method. 
where $\operatorname{sgn}(\zeta)$ extracts the sign of the zeta potential, $N_{a}$ is the Avogadro constant, $k_{b}$ is the Boltzmann constant, $T$ is the temperature, $c_{o(i)}$ is the bulk concentration of ionic species, $z_{i}$ is the ion charge number of ionic species, and $e$ is the electron charge.

All the microcapillaries were flushed with acetone followed by DI water and the solutions to be measured before use. The capillary tube and reservoir connecting to the cathode were filled with $0.5 \mathrm{mM}$ solution while reservoir connecting to the anode was filled with $0.475 \mathrm{mM}$ solution (5\% concentration difference) (see Fig. 1). Electric potential of $1000 \mathrm{~V}$ was applied across the two reservoirs to induce EOF. Experiments were conducted five times for each data point to ensure consistency and reliability of results. The zeta potentials of all the solutions were calculated through the displacement times with Eq. (2). The surface charge densities of the solutions were then obtained by substituting the calculated zeta potentials into Eq. (3). Table II shows the measured zeta potentials and surface charge densities for the solutions.

\section{Displacement flow of two dissimilar ionic solutions}

Two solution pairs, namely $0.5 \mathrm{mM} \mathrm{KCl}-\mathrm{NaCl}$ and $0.5 \mathrm{mM} \mathrm{CaCl}_{2}-\mathrm{NaCl}$, were selected for the investigation of displacement flows between symmetric electrolytes with dissimilar cations and asymmetric-symmetric electrolytes with dissimilar cations, respectively. The concentrations for all the solutions are set to be identical so that the effect of ionic species type on EOF behavior can be examined.

Current monitoring experiments as described in Sec. II B 1 were conducted to monitor the flow behavior through the current-time curve. Electric potential of $1000 \mathrm{~V}$ was applied across the two reservoirs to generate displacement flow of two opposing directions, i.e., $0.5 \mathrm{mM} \mathrm{KCl}$ displaces $0.5 \mathrm{mM} \mathrm{NaCl}$ and $0.5 \mathrm{mM} \mathrm{NaCl}$ displaces $0.5 \mathrm{mM} \mathrm{KCl}$. These experiments were conducted for the two solution pairs. For each case, displacement flows in two different directions were conducted five times each to ensure consistency and reliability of results.

In the subsequent discussion, solution which initially resides in the microcapillary before the displacement flow is called the residing electrolyte (RE). The solution which is placed in the inlet reservoir and transported into the channel to displace the residing electrolyte is called the displacing electrolyte (DE). In this investigation, the responses for the two different flow directions are compared to demonstrate the hysteresis effect.

Since the concentrations and conductivities of the solutions used for the experiments were low, the temperature rise due to Joule heating can be considered insignificant in our investigation. ${ }^{32}$ A conservative estimate of Joule heating can be calculated from the energy balance between the energy generation $E_{g}$ and the energy storage $\Delta E_{s t}$ in the liquid. ${ }^{33}$ For the chosen experimental parameters, the worst case scenario has an estimated temperature rise of $0.08^{\circ} \mathrm{C}$, which is negligible.

\section{EXPERIMENTAL RESULTS}

Examples of current-time curves for the displacement flow of $0.5 \mathrm{mM} \mathrm{KCl}-\mathrm{NaCl}$ and $0.5 \mathrm{mM} \mathrm{CaCl}_{2}-\mathrm{NaCl}$ in two different directions are shown in Figs. 2(a) and 2(b), respectively. As opposed to the displacement flow of the same solutions with different concentrations, the current-time curve for two different ionic solutions exhibits an abrupt change of gradient during the displacement flow. Hence, the term "turning time" is introduced to describe this abrupt change, whereby the magnitude of the second time derivative of current is maximum. The displacement time is determined by the time required for the current to reach a steady value. The

TABLE II. Measured zeta potentials and surface charge densities for various solutions.

\begin{tabular}{lcc}
\hline \hline Solution & Zeta potential $(\mathrm{mV})$ & ${\text { Surface charge density }\left(\mathrm{mC} \cdot \mathrm{m}^{-2}\right)}^{-2}$ \\
\hline $0.5 \mathrm{mM} \mathrm{KCl}$ & -56.9 & -3.57 \\
$0.5 \mathrm{mM} \mathrm{NaCl}$ & -54.3 & -3.35 \\
$0.5 \mathrm{mM} \mathrm{CaCl}_{2}$ & -30.6 & -3.84 \\
\hline \hline
\end{tabular}



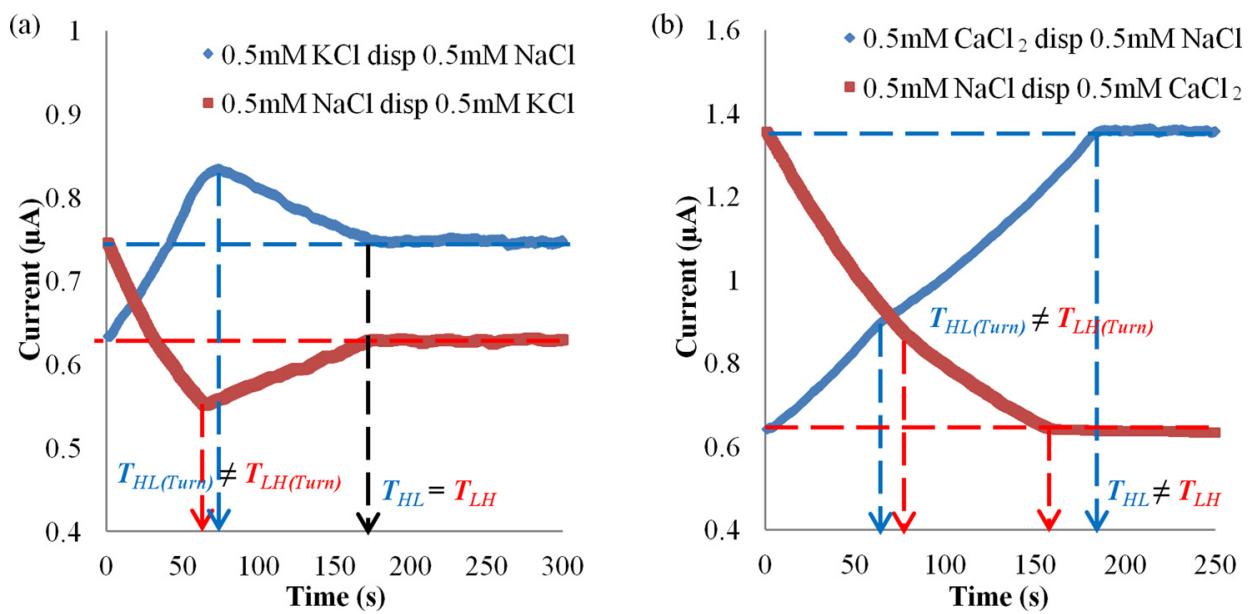

FIG. 2. Current-time curves for displacement flow of (a) $0.5 \mathrm{mM} \mathrm{KCl}-\mathrm{NaCl}$ and (b) $0.5 \mathrm{mM} \mathrm{CaCl}_{2}-\mathrm{NaCl}_{\text {in }}$ two directions.

turning and displacement times of the current-time curves for the two solution pairs in two different directions are represented by Figs. 3(a) and 3(b).

Student's $t$-test was performed on the data to examine if the mean turning times, as well as the displacement times, between the two flow directions differ significantly for the two cases. Let $T_{L H(\text { Turn })}$ be the turning time and $T_{L H}$ be the displacement time for low conductivity solution displacing high conductivity solution, and $T_{H L(T u r n)}$ be the turning time and $T_{H L}$ be the displacement time for high conductivity solution displacing low conductivity solution. The null hypothesis $H_{O}$ suggests that $T_{L H(\text { Turn })}$ (or $T_{L H}$ ) is the same as $T_{H L(T u r n)}$ (or $T_{H L}$ ) while the alternative hypothesis $H_{1}$ suggests otherwise. The $t$-score is calculated by

$$
t_{s}=\frac{\bar{T}_{L H(\text { Turn }) / L H}-\bar{T}_{H L(\text { Turn }) / H L}}{\sqrt{\frac{s_{L H(T u r n) / L H}^{2}}{n}-\frac{s_{H L(T u r n) / H L}^{2}}{n}}},
$$

where $\bar{T}_{L H(T u r n)}, \bar{T}_{H L(T u r n)}, \bar{T}_{L H}$, and $\bar{T}_{H L}$ are the sample means of $T_{L H(T u r n)}, T_{H L(T u r n)}, T_{L H}$, and $T_{H L}$ respectively; $s_{L H(T u r n)}, s_{H L(T u r n)}, s_{L H}$, and $s_{H L}$ are the sample standard deviations of $T_{L H(T u r n)}, T_{H L(T u r n)}, T_{L H}$ and $T_{H L}$, respectively; and $n$ is the number of samples.

The $t$-scores calculated from the experimental data are shown in Table III. Since the sample size for each data group is 5 , the degrees of freedom (dof) for $t$-score is 8 . The critical
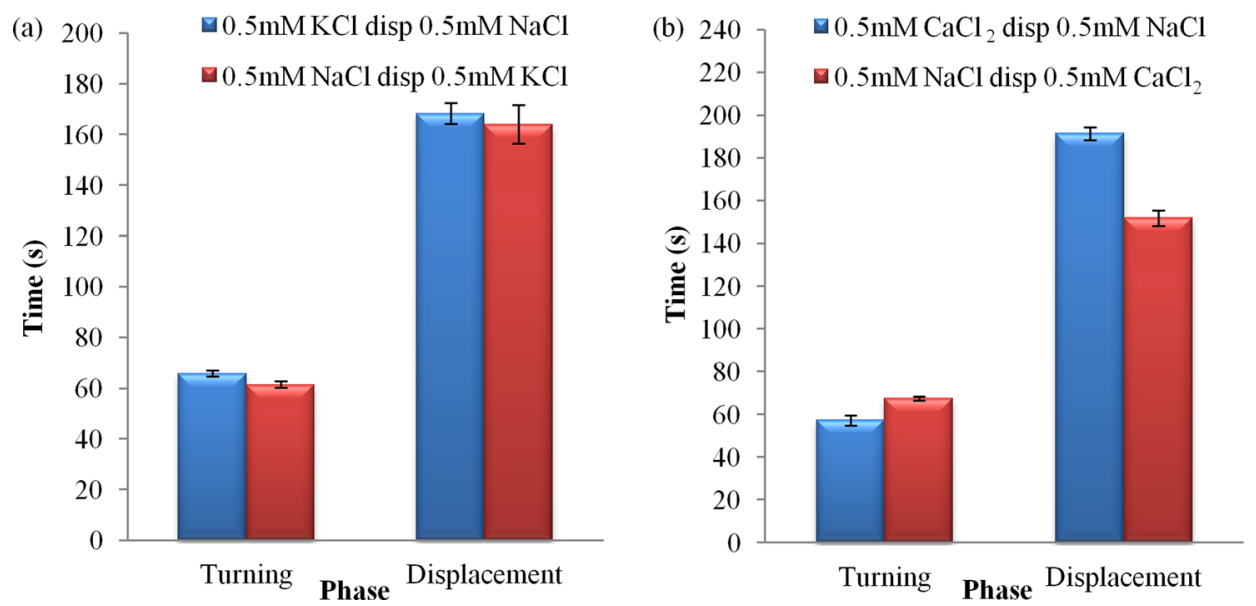

FIG. 3. Turning and displacement times for displacement flow of (a) $0.5 \mathrm{mM} \mathrm{KCl}-\mathrm{NaCl}$ and (b) $0.5 \mathrm{mM} \mathrm{CaCl}{ }_{2}-\mathrm{NaCl}$ in two directions. 
TABLE III. $t$-scores for turning and displacement times calculated from experimental data. Concentrations of all solutions are $0.5 \mathrm{mM}$.

\begin{tabular}{lcc}
\hline \hline Solution pair & $t$-score for turning time & $t$-score for displacement time \\
\hline $\mathrm{KCl}-\mathrm{NaCl}$ & -5.75 & -1.12 \\
$\mathrm{CaCl}_{2}-\mathrm{NaCl}$ & 8.86 & -18.53 \\
\hline \hline
\end{tabular}

$t$-scores for $1 \%$ significance level in a two tails test are \pm 3.36 . The magnitudes of all the $t$-scores in Table III, except that for the displacement times of $\mathrm{KCl}-\mathrm{NaCl}$ solution pair, are higher than the magnitude of the critical $t$-score. This indicates that the probability for both the observed turning and displacement time differences to be caused by random errors is very small (less than 1\%) and thus $H_{o}$ is rejected.

For $\mathrm{KCl}-\mathrm{NaCl}$ solution pair, the difference between the displacement times is not statistically significant. However, the mean turning time difference between the two different flow directions was measured to be $7 \%$. In the case of $\mathrm{CaCl}_{2}-\mathrm{NaCl}$ solution pair, the mean turning time and the mean displacement time for $\mathrm{NaCl}$ displacing $\mathrm{CaCl}_{2}$ is $18 \%$ longer and $21 \%$ shorter, respectively, than the flow in the reverse direction.

The coexistence of the turning and displacement times in the current-time curve indicates that EOF involving solution pair with dissimilar ionic species consists of two distinct phases. The hysteretic behavior in electroosmotic displacement flow with dissimilar ionic solutions will be explained in Sec. IV C with the support of numerical simulations.

\section{NUMERICAL MODEL}

Our group had previously conducted numerical studies with finite element method (FEM) based on the Poisson-Nernst-Planck (PNP) model with modified boundary conditions to explain the hysteresis phenomenon of similar solutions with large concentration difference. ${ }^{28}$ This model adequately describes the two-fluid displacement flow as it considers the changes of ion concentrations near the EDL due to diffusion, electromigration, and convection. Unlike other conventional models, the zeta potential and ion distributions are not specified a priori. Therefore, the model can simulate the variation of zeta potential and ion concentrations along the microchannel during the two-fluid displacement flow. In this study, this numerical model will be applied to investigate the EOF hysteresis involving dissimilar ionic solutions.

The simulations were implemented on COMSOL Multiphysics software. The simulation domain (see Fig. 4) is a straight microchannel with diameter of $100 \mu \mathrm{m}$ and length of $0.5 \mathrm{~cm}$. The fluid flow is assumed to be axisymmetric about the center axis of the cylindrical channel. As the governing equations for applied electric potential, wall potential, ion distributions, and fluid flow are strongly coupled, high computational resources are required. Thus, to minimize the computational time, the length of the channel is reduced to 16 times less than the length of the microcapillaries employed in the experiments. Since it had been experimentally shown that the percentage of displacement time difference is not dependent on the length of the

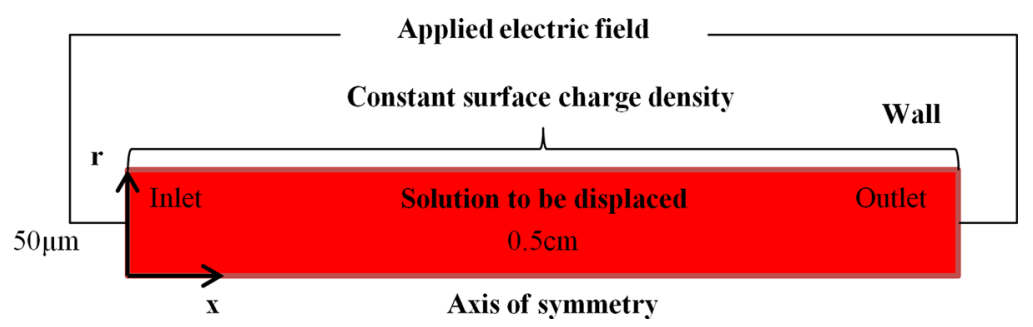

FIG. 4. Simulation domain (not drawn to scale). 
microcapillary or the voltage applied, ${ }^{28}$ the model will provide good representations of the experimental flow behaviors.

The simulation model was meshed with 24000 quadrilateral elements (24 and 1000 edge elements in the radial and axial directions, respectively). The size of the elements varies exponentially in the radial direction such that the elements near the EDL are fine enough to capture the steep changes of variables. The applied potential, electrostatic potential and ion concentrations were discretized with second order elements, while the pressure and velocity were discretized with linear elements. Convergence test was performed with higher number of elements for steady-state solutions and the numerical error is negligible for this mesh selection.

\section{A. Governing equations}

Applying external electrical field parallel to the wall generates a current across the microchannel. Charge conservation requires the divergence of current density $\mathbf{i}$ to be zero with the assumption that there is no source or sink in the medium,

$$
\nabla . \mathbf{i}=0 .
$$

The relation of the current density $\mathbf{i}$ and the transport of ions is given as

$$
\nabla \cdot\left[\sigma \nabla \phi+F \sum z_{i} D_{i} \nabla c_{i}-\boldsymbol{u} F \sum z_{i} c_{i}\right]=0,
$$

where the solution conductivity $\sigma$ can be described as $F \sum z_{i} u_{m(i)} c_{i}, \phi$ is the applied electric potential, $F$ is the Faraday constant, $D_{i}$ is the diffusion coefficient of ionic species, $c_{i}$ is the concentration of ionic species and $\boldsymbol{u}$ is the fluid velocity. The conductivity of the simulation domain is not constant but varying with the concentrations of ions. Eq. (6) consists of the electromigrative, diffusive, and convective currents whereby the first term is the major contributor; the other two terms may be neglected due to their small magnitudes. Hence, Eq. (6) is reduced to the Laplace equation, which governs the applied electric potential $\phi$,

$$
\nabla \cdot(\sigma \nabla \phi)=0 .
$$

The intrinsic wall potential distribution $\psi$ is given by the Poisson equation, which is written as

$$
\nabla \cdot \nabla \psi=-\frac{\rho_{\mathrm{e}}}{\varepsilon_{\mathrm{r}} \varepsilon_{\mathrm{o}}},
$$

where the net charge density $\rho_{e}=F \sum c_{i} z_{i}$. Since the net charge density is governed by the concentrations of ions which are varying in two-fluid displacement flow, the zeta potential has to be allowed to vary according to the local net charge density. Thus, constant surface charge is specified at the wall (instead of constant zeta potential) to capture the variation of zeta potential during the two-fluid displacement flow.

The transports of all the ionic species are simulated by the Nernst-Planck (NP) equation. It states that the change of ion concentration with time is governed by the gradients of three types of fluxes, namely diffusive, electromigrative, and convective fluxes. NP equation may be written as

$$
\frac{\partial c_{i}}{\partial t}+\nabla \cdot\left[-D_{i} \nabla c_{i}-u_{m(i)} c_{i} \nabla(\phi+\psi)\right]=-\boldsymbol{u} \cdot \nabla c_{i},
$$

where $u_{m(i)}$ is the ionic mobility.

The fluid flow for an incompressible Newtonian fluid is described by the Navier-Stokes (NS) and continuity equations in Eq. (10) and (11),

$$
\rho \frac{\partial \boldsymbol{u}}{\partial t}+\rho \boldsymbol{u} . \nabla \boldsymbol{u}=-\nabla p+\mu \nabla^{2} \boldsymbol{u}+\rho_{e}[-\nabla(\phi+\psi)],
$$




$$
\nabla \cdot \boldsymbol{u}=0
$$

where $\rho$ is the fluid density, $p$ is the pressure, and $\rho_{e}$ is the net charge density. The electric body force term (third term on the right side of Eq. (10)) consists of the product of the net charge density and the electric field, which is the negative divergence of the superposition of applied electric potential and wall potential. In microfluidics, the Reynolds number is typically less than 1, thus the inertial term is usually ignored and Stokes flow is assumed.

The NS and continuity equations have to be solved simultaneously with Laplace, Poisson, and NP equations to obtain the flow field. This is because the applied and intrinsic electric potentials, ion concentrations, and flow velocity are strongly coupled in EOF. The symbols and values of parameters used in the numerical simulations are given in Table IV.

\section{B. Boundary and initial conditions}

The governing equations have to be solved simultaneously first to obtain the steady-state solution of a single fluid EOF. The steady-state solution is then set as the initial condition for solving the time-dependent problem of two-fluid displacement flow. The boundary conditions for the steady-state numerical model for single fluid EOF are listed in Table V. A voltage of $62.5 \mathrm{~V}$ is set at the inlet to establish an electric field of $125 \mathrm{~V} \cdot \mathrm{cm}^{-1}$ across the microchannel similar to that in the experiment. The surface charge of the wall is specified to be the average value based on the mean surface charge densities (see Table II) of the two solutions involved in the displacement flow. It is assumed that the surface charge density is constant regardless of the concentrations of the solutions during the course of the two-fluid displacement flow. ${ }^{27}$ Table VI shows the surface charge densities $\sigma_{s}$ that are prescribed on the channel wall for different solution pairs.

The ion concentrations at the inlet and outlet of simulation domain are assumed to follow Boltzmann distribution under the effect of intrinsic wall potential $\psi$. The electric body force

TABLE IV. Symbols and values of parameters used in numerical simulations.

\begin{tabular}{|c|c|c|}
\hline Parameter & Symbol (unit) & Value \\
\hline Faraday constant & $F\left(\mathrm{C} \cdot \mathrm{mol}^{-1}\right)$ & 96485 \\
\hline Relative permittivity & $\varepsilon_{r}$ & 80 \\
\hline Permittivity of free space & $\varepsilon_{o}\left(\mathrm{C} \cdot \mathrm{V}^{-1} \cdot \mathrm{m}^{-1}\right)$ & $8.85 \times 10^{-12}$ \\
\hline Solution concentration & $c_{o}\left(\mathrm{~mol} \cdot \mathrm{m}^{-3}\right)$ & 0.5 \\
\hline Diffusion coefficient of $\mathrm{Na}^{+}$ion & $D_{N a}^{+}\left(\mathrm{m}^{2} \cdot \mathrm{s}^{-1}\right)$ & $1.334 \times 10^{-9}$ \\
\hline Diffusion coefficient of $\mathrm{K}^{+}$ion & $D_{K}^{+}\left(\mathrm{m}^{2} \cdot \mathrm{s}^{-1}\right)$ & $1.957 \times 10^{-9}$ \\
\hline Diffusion coefficient of $\mathrm{Ca}^{2+}$ ion & $D_{C a}^{2+}\left(\mathrm{m}^{2} \cdot \mathrm{s}^{-1}\right)$ & $7.920 \times 10^{-10}$ \\
\hline Diffusion coefficient of $\mathrm{Cl}^{-}$ion & $D_{C l}{ }^{-}\left(\mathrm{m}^{2} \cdot \mathrm{s}^{-1}\right)$ & $2.032 \times 10^{-9}$ \\
\hline Ionic mobility of $\mathrm{Na}^{+}$ion & $u_{m(\mathrm{Na}}{ }^{+},\left(\mathrm{m}^{2} \cdot \mathrm{V}^{-1} \cdot \mathrm{s}^{-1}\right)$ & $5.194 \times 10^{-8}$ \\
\hline Ionic mobility of $\mathrm{K}^{+}$ion & $u_{m(K}{ }^{+},\left(\mathrm{m}^{2} \cdot \mathrm{V}^{-1} \cdot \mathrm{s}^{-1}\right)$ & $7.930 \times 10^{-8}$ \\
\hline Ionic mobility of $\mathrm{Ca}^{2+}$ ion & $u_{m(C a}^{2+},\left(\mathrm{m}^{2} \cdot \mathrm{V}^{-1} \cdot \mathrm{s}^{-1}\right)$ & $6.169 \times 10^{-8}$ \\
\hline Ionic mobility of $\mathrm{Cl}^{-}$ion & $\left.u_{m(C l}\right)\left(\mathrm{m}^{2} \cdot \mathrm{V}^{-1} \cdot \mathrm{s}^{-1}\right)$ & $-7.919 \times 10^{-8}$ \\
\hline Ionic charge number of $\mathrm{Na}^{+}$ion & $z_{\mathrm{Na}}^{+}$ & +1 \\
\hline Ionic charge number of $\mathrm{K}^{+}$ion & $z_{K}^{+}$ & +1 \\
\hline Ionic charge number of $\mathrm{Ca}^{2+}$ ion & $z_{\mathrm{Ca}}^{2+}$ & +2 \\
\hline Ionic charge number of $\mathrm{Cl}^{-}$ion & $z_{C l}^{-}$ & -1 \\
\hline Temperature & $T(\mathrm{~K})$ & 298 \\
\hline Electron charge & $e(\mathrm{C})$ & $1.602 \times 10^{-19}$ \\
\hline Boltzmann constant & $k_{b}\left(\mathrm{~m}^{2} \cdot \mathrm{kg} \cdot \mathrm{s}^{-2} \cdot \mathrm{K}^{-1}\right)$ & $1.381 \times 10^{-23}$ \\
\hline Density of water & $\rho\left(\mathrm{kg} \cdot \mathrm{m}^{-3}\right)$ & 1000 \\
\hline Viscosity of water & $\mu\left(\mathrm{kg} \cdot \mathrm{m}^{-1} \cdot \mathrm{s}^{-1}\right)$ & $8.90 \times 10^{-4}$ \\
\hline Avogadro constant & $N_{a}\left(\mathrm{~mol}^{-1}\right)$ & $6.022 \times 10^{23}$ \\
\hline
\end{tabular}


TABLE V. Boundary conditions for steady-state numerical model for single fluid electroosmotic flow.

\begin{tabular}{lcc}
\hline \hline Variable & Condition & Boundary \\
\hline Applied potential $\phi$ & $\phi=62.5 \mathrm{~V}$ & Inlet \\
& $\phi=0 \mathrm{~V}$ & Outlet \\
& $\mathbf{n} \cdot \nabla \phi=0$ & Wall and symmetry \\
Electrostatic potential $\psi$ & $\mathbf{n} \cdot \nabla \psi=0$ & Inlet, outlet, and symmetry \\
& $\mathbf{n} \cdot \nabla \psi=-\frac{\sigma_{s}}{\varepsilon_{r} \varepsilon_{o}}$ \\
Concentrations of ions $c_{i}$ & $c_{i}=c_{o(i)} \exp \left(\frac{-z_{i} e \psi}{k_{b} T}\right)$ & Wall \\
& $-\mathbf{n} \cdot\left[-D_{i} \nabla c_{i}-u_{m(i)} c_{i} \nabla(\phi+\psi)+\boldsymbol{u} c_{i}\right]=0$ & Inlet and oulet \\
Flow velocity $\boldsymbol{u}$ and Pressure $p$ & $\mathbf{u}=0$ & Wall and symmetry \\
& $\mathbf{n} \cdot \boldsymbol{u}=0^{\mathrm{a}}$ & Wall \\
& $p=0$ & Symmetry \\
\hline \hline
\end{tabular}

${ }^{a} \mathbf{n}$ is the unit vector normal to the boundary.

(third term on the right side of Eq. (10)) is non-linear because both $\rho_{e}$ and $\boldsymbol{E}$ are functions of $\psi$. To simplify the numerical solving of Eq. (10), it is assumed that the wall potential induced body force is balanced by the pressure gradient in the radial direction. ${ }^{34}$ Therefore, pressures at the inlet and outlet are set to zero, and $\psi$ is removed from $\boldsymbol{E}$ in the body force term of Eq. (10).

After obtaining the steady-state solution, the boundary conditions at the inlet are modified to simulate two-fluid displacement flow with the steady-state solution as the initial condition. The inlet boundary conditions for the concentrations of ions are changed from that of RE to that of DE by ramping in an arbitrarily short time of $0.01 \mathrm{~s}$. Simulations for the displacement flows of $0.5 \mathrm{mM} \mathrm{KCl}-\mathrm{NaCl}$ and $0.5 \mathrm{mM} \mathrm{CaCl}_{2}-\mathrm{NaCl}$ in the two different directions were performed to obtain the time-dependent flow solutions.

\section{Numerical results}

\section{Symmetric electrolytes with dissimilar cations: $\mathrm{KCl}-\mathrm{NaCl}$ solution pair}

The simulated current-time curves for the displacement flow of $0.5 \mathrm{mM} \mathrm{KCl}$ (higher conductivity) and $0.5 \mathrm{mM} \mathrm{NaCl}$ (lower conductivity) in both directions (see Fig. 5(a)) indicate that $T_{H L(\text { Turn })}$ is $15 \%$ longer than $T_{L H(T u r n)}$ and $T_{H L}$ is $4 \%$ longer than $T_{L H}$. However, $t$-test based on the experimental results suggests that the displacement time difference is not statistically significant. This small difference is not detectable in the experiments as it is in the range of experimental errors.

The simulated and experimental current-time curves (see Fig. 5(b)) are compared by normalizing the currents and times in both cases. The currents are normalized with the steady-state currents for the two solutions, whereas the times are normalized by the time for $\mathrm{KCl}$ to fully displace $\mathrm{NaCl}\left(T_{H L}\right)$. Fig. 5(b) shows that the simulation results match almost exactly with the experimental results and the displacement time difference is indeed not significant.

The current increases or decreases beyond the range of the equilibrium currents during the displacement flow (see Fig. 5(a)). To explain this current behavior and the turning time difference, evolution of ion distributions throughout the displacement flow is examined through the simulation for the two flow directions. The displacement flow can be separated into two distinct

TABLE VI. Prescribed wall surface charge densities for different solution pairs. Concentrations of all solutions are $0.5 \mathrm{mM}$.

\begin{tabular}{lc}
\hline \hline Solution pair & Surface charge density $\left(\mathrm{mC} \cdot \mathrm{m}^{-2}\right)$ \\
\hline $\mathrm{KCl}-\mathrm{NaCl}$ & -3.46 \\
$\mathrm{CaCl}_{2}-\mathrm{NaCl}$ & -3.60 \\
\hline \hline
\end{tabular}



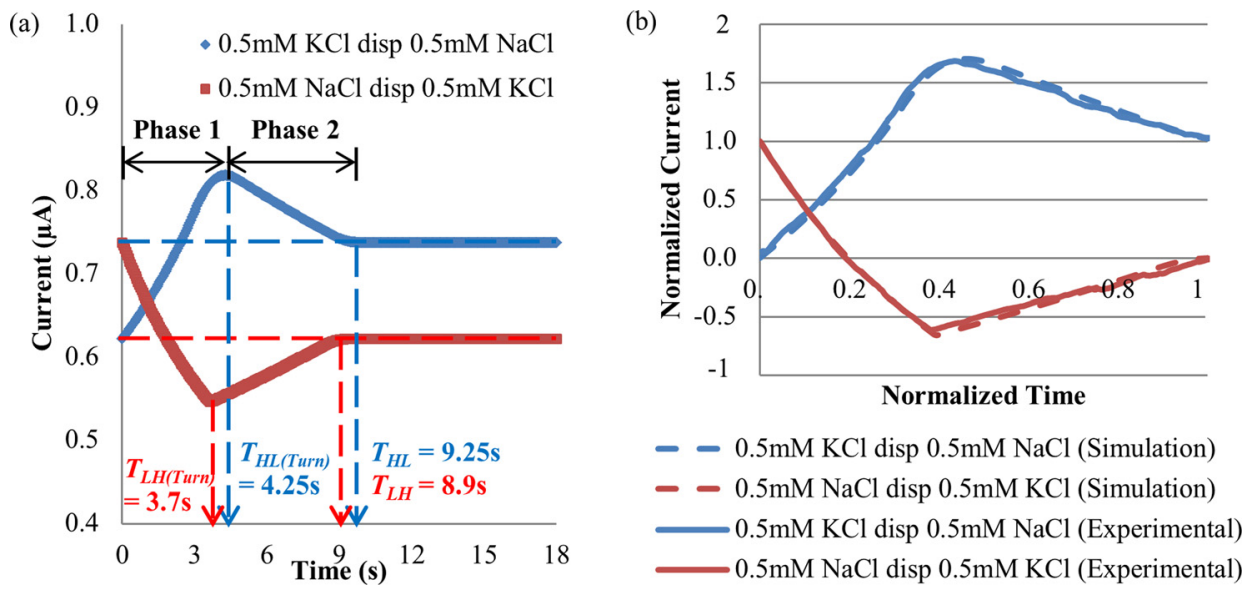

FIG. 5. (a) Simulated current-time curves for displacement flow of $0.5 \mathrm{mM} \mathrm{KCl}-\mathrm{NaCl}$ in both directions and (b) comparison between simulation and experimental results. Currents and displacement times are normalized with the two steadystate current values and time for $\mathrm{KCl}$ to fully displace $\mathrm{NaCl}\left(T_{H L}\right)$, respectively.

phases with the turning time of current-time curve; namely, Phase 1 before the turning time and Phase 2 after the turning time (see Fig. 5(a)).

When $\mathrm{KCl}(\mathrm{DE})$ displaces $\mathrm{NaCl}(\mathrm{RE})$, accumulation of $\mathrm{K}^{+}$and $\mathrm{Cl}^{-}$occurs at the rear of the interface during Phase 1 (see Fig. 7(a)). The ion accumulation effect is caused by the difference in conductivity of the two solutions, which arises from the ionic mobility difference between the cations in DE and RE. The ionic mobilities $u_{m(i)}$ for $\mathrm{K}^{+}$and $\mathrm{Na}^{+}$are $7.930 \times 10^{-8} \mathrm{~m}^{2} \cdot \mathrm{V}^{-1} \cdot \mathrm{s}^{-1}$ and $5.194 \times 10^{-8} \mathrm{~m}^{2} . \mathrm{V}^{-1} \cdot \mathrm{s}^{-1}$, respectively. The conductivity $\sigma$ of $\mathrm{KCl}$ solution $\left(75.0 \mu \mathrm{S} \cdot \mathrm{cm}^{-1}\right)$ is higher than $\mathrm{NaCl}$ solution $\left(63.3 \mu \mathrm{S} \cdot \mathrm{cm}^{-1}\right)$ due to the higher ionic mobility.

The applied potential generates high electric field in RE with lower conductivity and low electric field in DE with higher conductivity. The difference in electric field in the two solutions causes the incoming electromigrative flux (third term on the left side of Eq. (9)) of $\mathrm{Cl}^{-}$ ions from RE to be higher than the outgoing flux in DE. This electromigrative flux gradient at the interface leads to the accumulation of $\mathrm{Cl}^{-}$(with concentration increasing from $0.5 \mathrm{mM}$ to $0.62 \mathrm{mM}$ ) as shown in Fig. 6(a). To maintain charge neutrality as dictated by Eq. (7), $\mathrm{K}^{+}$ion concentration in the vicinity is increased from $0.5 \mathrm{mM}$ to $0.62 \mathrm{mM}$ to match the concentration of $\mathrm{Cl}^{-}$(see Fig. 7(a)). The accumulation of ions causes the total conductivity across the microchannel and thus current to increase beyond the equilibrium value (see Fig. 5(a)).

On the contrary, when $\mathrm{NaCl}$ (DE) displaces $\mathrm{KCl}(\mathrm{RE})$, depletion of $\mathrm{Na}^{+}$and $\mathrm{Cl}^{-}$ions occurs behind the interface between the two solutions during Phase 1 (see Fig. 7(c)). The ion depletion effect is similarly caused by the difference in conductivity of DE and RE, which is
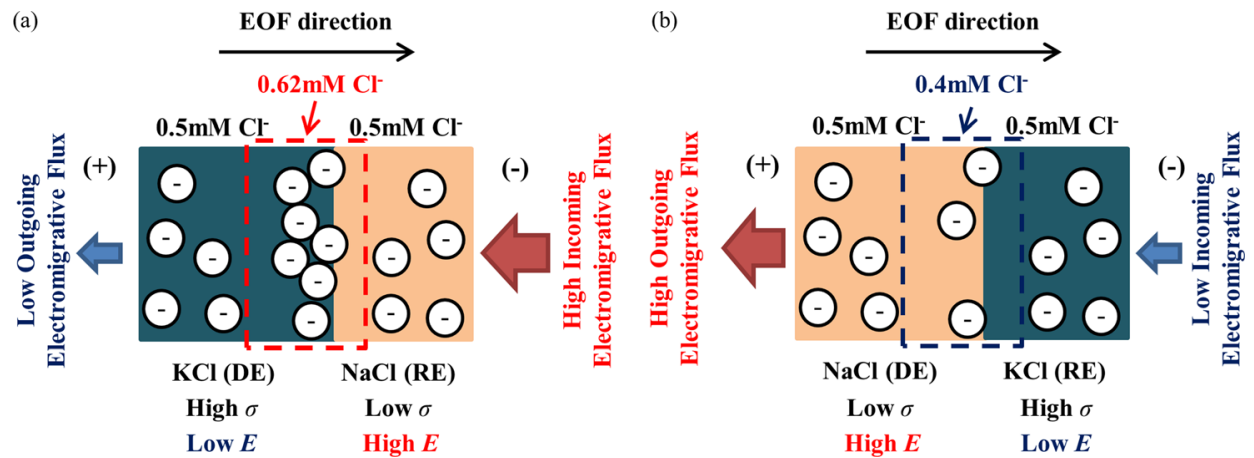

FIG. 6. Schematic drawings to illustrate $\mathrm{Cl}^{-}$ion concentration adjustment when (a) $0.5 \mathrm{mM} \mathrm{KCl}$ displaces $0.5 \mathrm{mM} \mathrm{NaCl}$ and (b) $0.5 \mathrm{mM} \mathrm{NaCl}$ displaces $0.5 \mathrm{mM} \mathrm{KCl} . \boldsymbol{E}$ and $\sigma$ denote electric field and conductivity, respectively. Positive ions are not shown. 

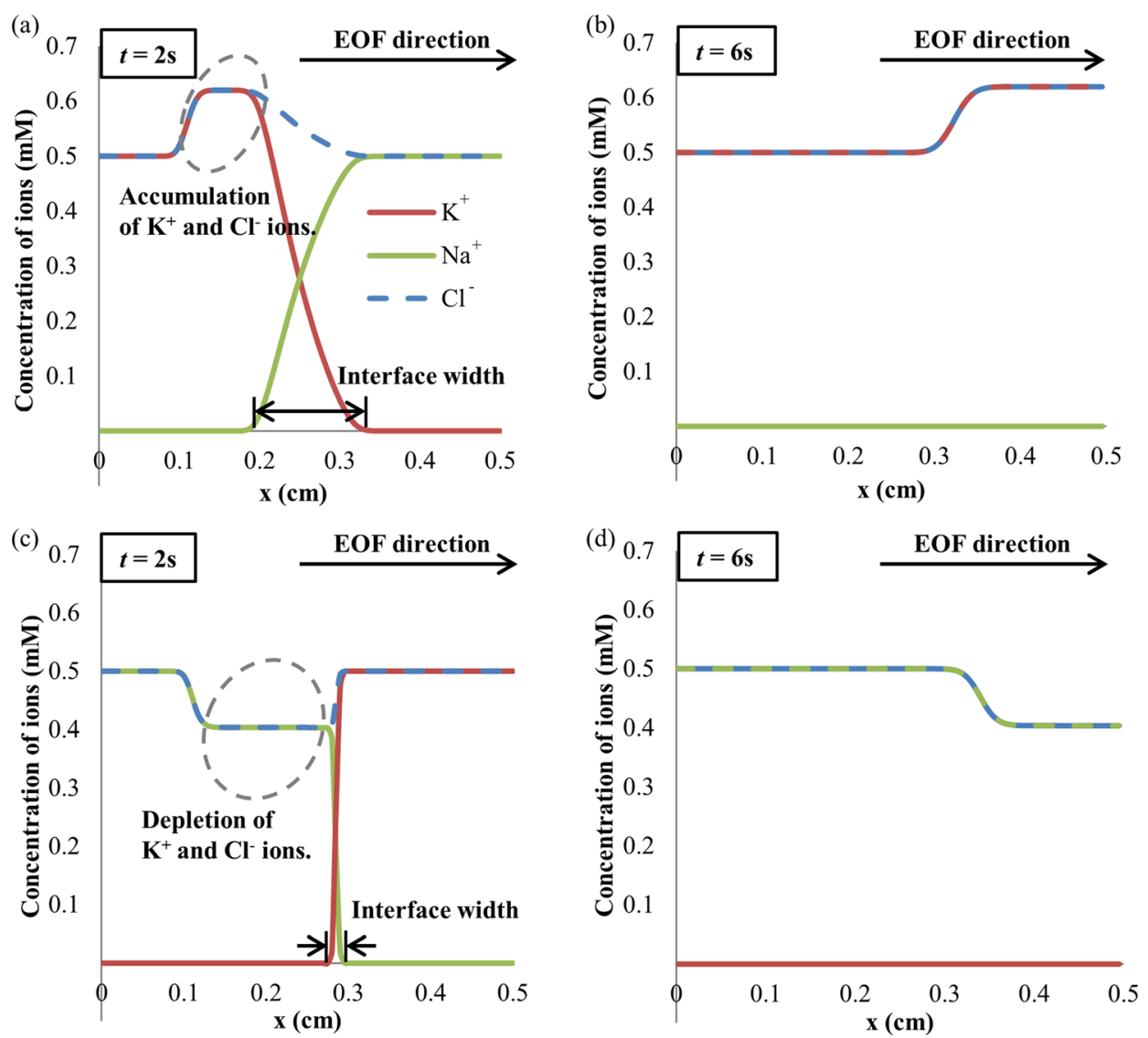

FIG. 7. Simulated ion concentrations at axis of symmetry along microchannel when (a) $0.5 \mathrm{mM} \mathrm{KCl}$ displaces $0.5 \mathrm{mM}$ $\mathrm{NaCl}$ in Phase $1(t=2 \mathrm{~s})$ and (b) Phase $2(t=6 \mathrm{~s})$, and (c) $0.5 \mathrm{mM} \mathrm{NaCl}$ displaces $0.5 \mathrm{mM} \mathrm{KCl}$ in Phase $1(t=2 \mathrm{~s})$ and (d) Phase $2(t=6 \mathrm{~s})$.

induced by the ionic mobility difference between the cations. The applied potential generates lower electric field in RE with higher conductivity. Therefore, the incoming electromigrative flux of $\mathrm{Cl}^{-}$ions from RE is lower than the outgoing flux in DE, resulting in the depletion of $\mathrm{Cl}^{-}$ions (with concentration decreasing from $0.5 \mathrm{mM}$ to $0.4 \mathrm{mM}$ ) as shown in Fig. 6(b). The depletion of ions causes the total conductivity across the microchannel and thus current to decrease below the equilibrium value (see Fig. 5(a)).

In addition to the accumulation or depletion of ions, displacement flow of dissimilar ionic solutions also causes variation of interface widths between the two solutions depending on the flow direction (see Figs. 7(a) and 7(b)). Interface width is defined as the length of the region which contains both DE and RE. The interface widths obtained from the simulations for both flow directions are plotted in Fig. 8(c). Gradual widening of the interface width has been observed when $\mathrm{KCl}$ displaces $\mathrm{NaCl}$, while the interface width remains almost constant in the reverse direction.

The variation of interface widths is caused by the difference in electric field between DE and $\mathrm{RE}$. For $\mathrm{KCl}$ displacing $\mathrm{NaCl}$, electric field in the ion-crowded region is lower than $\mathrm{RE}$ due to its high conductivity (see Fig. 8(a)). As $\mathrm{K}^{+}$ions diffuse to the boundary of RE, it experiences high electric field. Therefore, $\mathrm{K}^{+}$ions start to migrate faster than the surrounding ions and penetrate into the RE region, resulting in a widened interfacial region.

On the contrary, when $\mathrm{NaCl}$ displaces $\mathrm{KCl}$, the ion-deficient region has higher electric field than $\mathrm{RE}$ as a result of its low conductivity (see Fig. 8(b)). Thus, as $\mathrm{Na}^{+}$ions diffuse to the boundary of RE, they decelerate back to DE due to the low electric field in the RE region. This results in a sharp and constant interfacial region. 

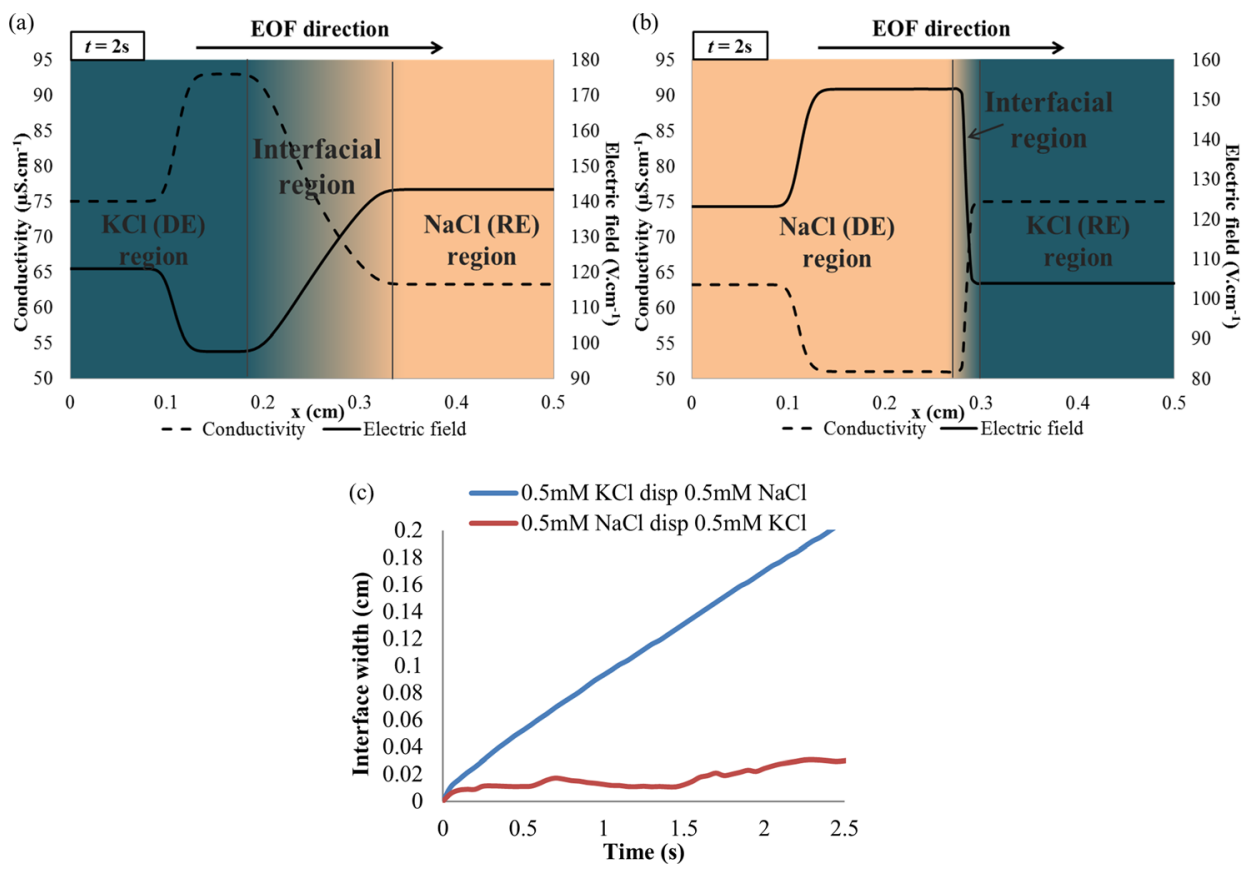

FIG. 8. Simulated conductivity and electric field at axis of symmetry along microchannel in Phase 1 ( $t=2 \mathrm{~s})$ when (a) $0.5 \mathrm{mM} \mathrm{KCl}$ displaces $0.5 \mathrm{mM}$ and (b) $0.5 \mathrm{mM} \mathrm{NaCl}$ displaces $0.5 \mathrm{mM} \mathrm{KCl}$. (c) Simulated interface widths in both flow directions.

The time for RE, including ions in the interface, to be fully displaced out of the microchannel is reflected as the turning time in the current-time curve. The average flow velocities $u_{\text {ave }}$ throughout Phase 1 for both flow directions are examined to explain the turning time difference observed in the simulations (see Fig. 5(a)). The average flow velocity is described as

$$
u_{\text {ave }}=\frac{Q}{\mathrm{~A}}
$$

where $Q$ is the flow rate obtained by integrating the $x$-velocity over the cross sectional area $\mathrm{A}$ of the microchannel.

For $\mathrm{KCl}-\mathrm{NaCl}$ solution pair, $u_{\text {ave }}$ for both directions during Phase 1 differ by less than 10\% (see Fig. 9(a)). Therefore, the dominating factor which contributes to the turning time
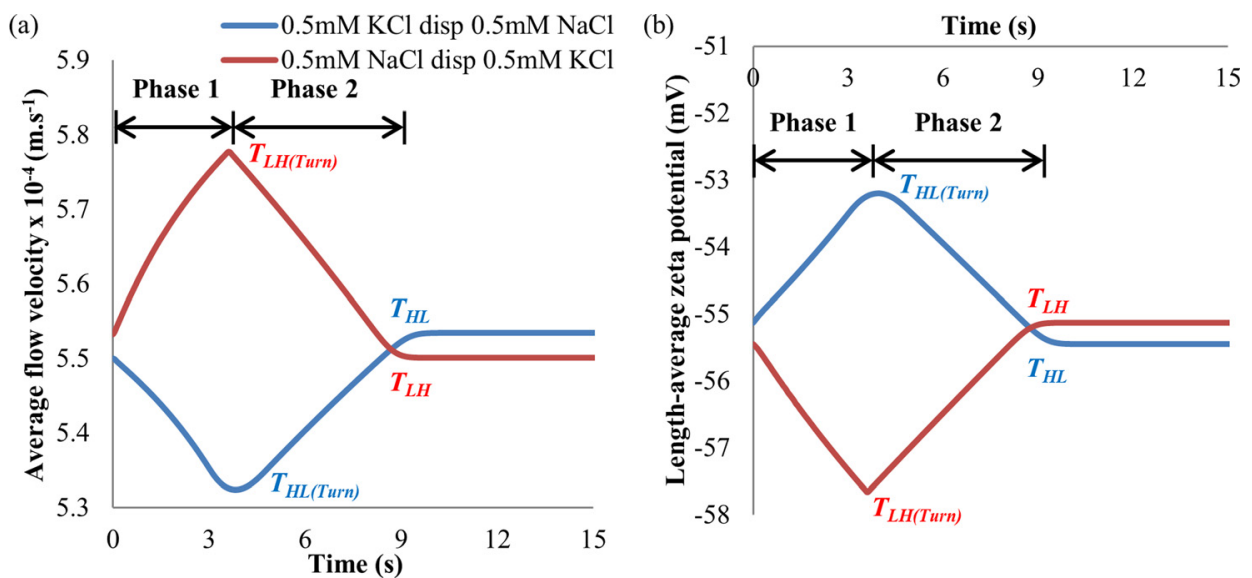

FIG. 9. Simulated (a) average flow velocity $u_{\text {ave }}$ and (b) length-average zeta potential $\bar{\zeta}$ for displacement flow of $0.5 \mathrm{mM}$ $\mathrm{KCl}-\mathrm{NaCl}$ in both flow directions. 
difference is the widening/sharpening effect of the interfacial region. The flow direction which generates wider interfacial region requires a longer time for the complete displacement of RE,

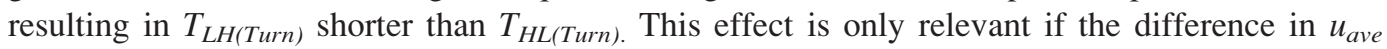
between the two flow directions is small.

The slight difference in $u_{\text {ave }}$ between the two flow directions during Phase 1 is attributed to the small difference in length-average zeta potential $\bar{\zeta}$ (see Fig. 9(b)). Tang et al. ${ }^{24}$ have derived an equation indicating that $u_{\text {ave }}$ is essentially the length-average electroosmotic velocity by combining Ohm's law and fluid mass conservation in the EOF of two solutions. This condition, together with Smoluchowski slip velocity equation (Eq. (1)), yields the direct relation of $u_{\text {ave }}$ and $\bar{\zeta}$. The length-average zeta potential can be defined as

$$
\bar{\zeta}=\frac{1}{L} \int_{0}^{L} \zeta(x) d x,
$$

where $\zeta(x)$ is the zeta potential, which is a function of $x$ position along the microchannel.

After RE is completely flushed out, DE of different concentrations remain in the microchannel for both flow directions. According to the simulations, $\mathrm{KCl}$ with concentration ranging from $0.5 \mathrm{mM}-0.62 \mathrm{mM}$ is formed in the channel for the case of $\mathrm{KCl}$ displacing $\mathrm{NaCl}$, while $\mathrm{NaCl}$ with concentration ranging from $0.4 \mathrm{mM}-0.5 \mathrm{mM}$ is produced in the reverse flow direction (see Figs. 7(b) and 7(d)).

Subsequent current changes during Phase 2 (after the turning time) are caused by the displacement flow of DE at different concentrations which are generated in Phase 1 from ion accumulation or depletion. Fig. 9(b) shows that $\bar{\zeta}$ for $0.5 \mathrm{mM}-0.62 \mathrm{mM} \mathrm{KCl}$ and $0.4 \mathrm{mM}-0.5 \mathrm{mM}$ $\mathrm{NaCl}$ differ insignificantly (by less than 10\%). The resultant small difference in $u_{\text {ave }}$ (see Fig. 9(a)) thereby generates a slight displacement time difference between the two flow directions which can only be detected in the numerical simulations, but not through the experiments.

\section{Asymmetric-symmetric electrolytes with dissimilar cations: $\mathrm{CaCl}_{2}-\mathrm{NaCl}$ solution pair}

The simulated current-time curves for the displacement flow of $0.5 \mathrm{mM} \mathrm{CaCl} \mathrm{C}_{2}$ (higher conductivity) and $0.5 \mathrm{mM} \mathrm{NaCl}$ (lower conductivity) in both directions (see Fig. 10(a)) show that $T_{L H(\text { Turn })}$ is $27 \%$ longer than $T_{H L(T u r n)}$ while $T_{H L}$ is $34 \%$ longer than $T_{L H}$. The simulated and experimental current-time curves (see Fig. 10(b)) are compared by normalizing the currents and times in both cases. The currents are normalized with the maximum and minimum currents whereas the times are normalized by the time for the ascending curve to reach a steady value $\left(T_{H L}\right)$. Fig. 10(b) shows that the simulation results agree very well with the experimental results.
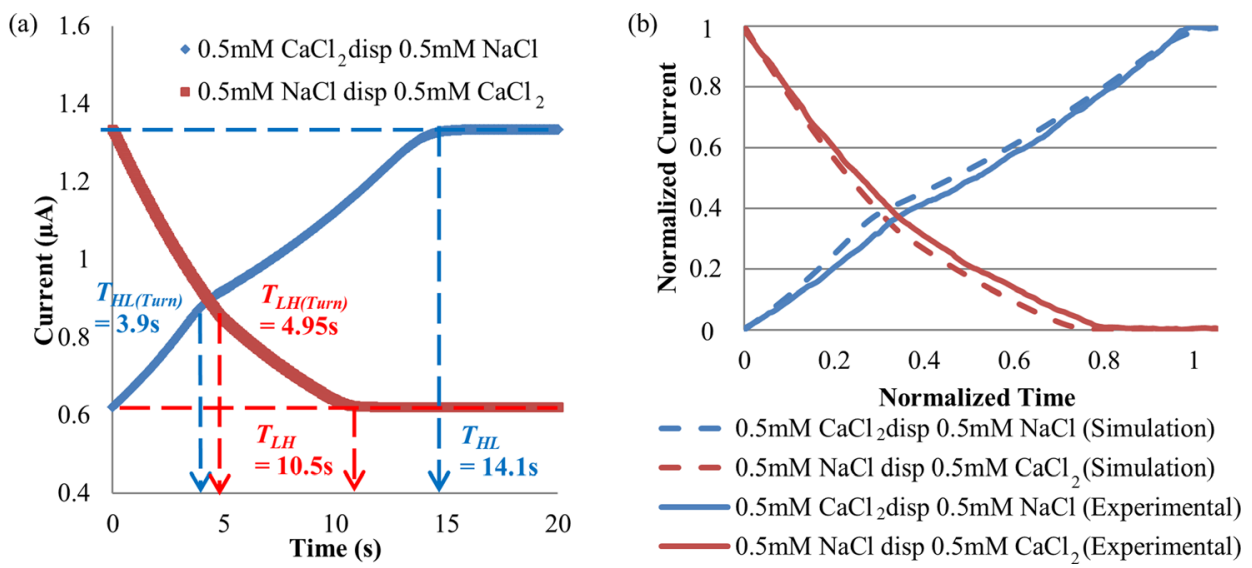

FIG. 10. (a) Simulated current-time curves for displacement flow of $0.5 \mathrm{mM} \mathrm{CaCl} 2-\mathrm{NaCl}$ in both directions and (b) comparison between simulation and experimental results. Currents and displacement times are normalized with the maximum and minimum currents and time for the ascending curve to reach a steady value $\left(T_{H L}\right)$, respectively. 
The current change is bounded within the range of the equilibrium currents during the displacement flow (see Fig. 10(a)). Similarly, the evolution of ion distributions is examined via the numerical simulation to explain the current behavior, as well as the turning and displacement time differences between the two flow directions. The conductivities $\sigma$ for $\mathrm{CaCl}_{2}$ and $\mathrm{NaCl}$ are $135.9 \mu \mathrm{S} \cdot \mathrm{cm}^{-1}$ and $63.3 \mu \mathrm{S} \cdot \mathrm{cm}^{-1}$, respectively. When $\mathrm{CaCl}_{2}$ (DE) displaces $\mathrm{NaCl}$ (RE), the applied potential generates lower electric field in $\mathrm{CaCl}_{2}$ (higher conductivity) and higher electric field in $\mathrm{NaCl}$ (lower conductivity) owing to the difference in conductivity.

The resultant electromigrative flux gradient changes $\mathrm{Cl}^{-}$ion concentration to $0.54 \mathrm{mM}$ behind the interfacial region as the ions transverse from RE to DE in Phase 1 (see Fig. 11(a)). However, the adjusted $\mathrm{Cl}^{-}$ion concentration is still lower than the $\mathrm{Cl}^{-}$ion concentration of DE. Therefore, the current does not rise beyond the equilibrium value (see Fig. 10(a)). To satisfy the electroneutrality condition, $\mathrm{Ca}^{2+}$ ion concentration changes from $0.5 \mathrm{mM}$ to $0.27 \mathrm{mM}$ to match the charges of $\mathrm{Cl}^{-}$ions at the rear of the interface as shown in Fig. 12(a).

Similar argument can be applied to the flow in the reverse direction, i.e., $\mathrm{NaCl}$ (DE) displacing $\mathrm{CaCl}_{2}$ (RE). At the vicinity of the interface between the two solutions, concentration of $\mathrm{Na}^{+}$and $\mathrm{Cl}^{-}$ions are adjusted to $0.9 \mathrm{mM}$ during Phase 1 as observed in Fig. 12(c). This adjustment is similarly caused by the difference in electric field between DE and RE, which is induced by the conductivity difference of the two solutions (see Fig. 11(b)).

In addition to the adjustment of the ion concentrations, interface width broadening occurs when $\mathrm{CaCl}_{2}$ displaces $\mathrm{NaCl}$. On the contrary, the interface width remains narrow and almost constant for $\mathrm{NaCl}$ displacing $\mathrm{CaCl}_{2}$ (see Fig. 13). The interface width difference is caused by the difference in electric field between $\mathrm{DE}$ and $\mathrm{RE}$ (similar to the case of $\mathrm{KCl}-\mathrm{NaCl}$ solution pair in Sec. IV C 1).

To examine the turning time difference, the average flow velocity $u_{\text {ave }}$ and length-average zeta potential $\bar{\zeta}$ for both flow directions are plotted in Fig. 14. The large variation of $\bar{\zeta}$ throughout the displacement flow arises as a result of the non-uniform zeta potential along the channel due to the ion adjustment effect. As depicted in Fig. 14(b), $\bar{\zeta}$ for $\mathrm{NaCl}$ displacing $\mathrm{CaCl}_{2}$ is $50 \%$ smaller than the flow in the reverse direction initially. The flow direction with higher $\bar{\zeta}$ thus generates higher $u_{\text {ave }}$ (see Fig. 14(a)), which requires a shorter time for the complete displacement of RE. These provide the explanation for $T_{L H(T u r n)}$ to be longer than $T_{H L(T u r n)}$ in the simulations. The widening/sharpening effect of the interfacial region does not affect the turning time difference significantly because the advective effect arising from the large difference in $u_{\text {ave }}$ is more dominant than the interfacial diffusive effect.

Upon complete displacement of RE, DE with different concentrations are left in the microchannel for the two flow directions. As obtained from the simulations, $\mathrm{CaCl}_{2}$ with concentration ranging from $0.27 \mathrm{mM}-0.5 \mathrm{mM}$ is produced in the channel for $\mathrm{CaCl}_{2}$ displacing $\mathrm{NaCl}$, while $\mathrm{NaCl}$ with concentration ranging from $0.5 \mathrm{mM}-0.9 \mathrm{mM}$ is formed in the reverse flow direction (see Figs. 12(b) and 12(d)).
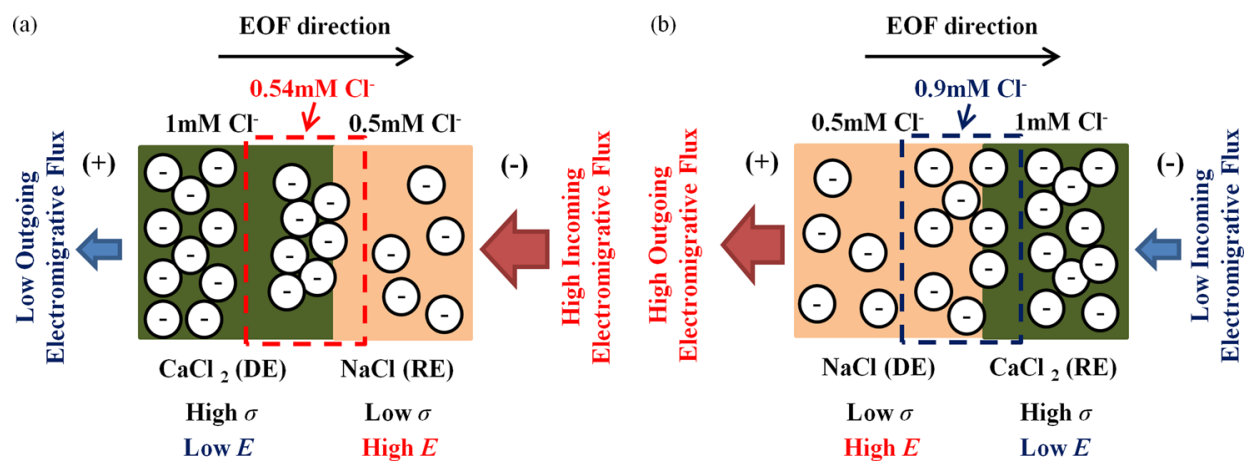

FIG. 11. Schematic drawings to illustrate $\mathrm{Cl}^{-}$ion concentration adjustment when (a) $0.5 \mathrm{mM} \mathrm{CaCl}$ displaces $0.5 \mathrm{mM}$ $\mathrm{NaCl}$ and (b) $0.5 \mathrm{mM} \mathrm{NaCl}$ displaces $0.5 \mathrm{mM} \mathrm{CaCl}_{2} . \boldsymbol{E}$ and $\sigma$ denote electric field and conductivity, respectively. Positive ions are not shown. 

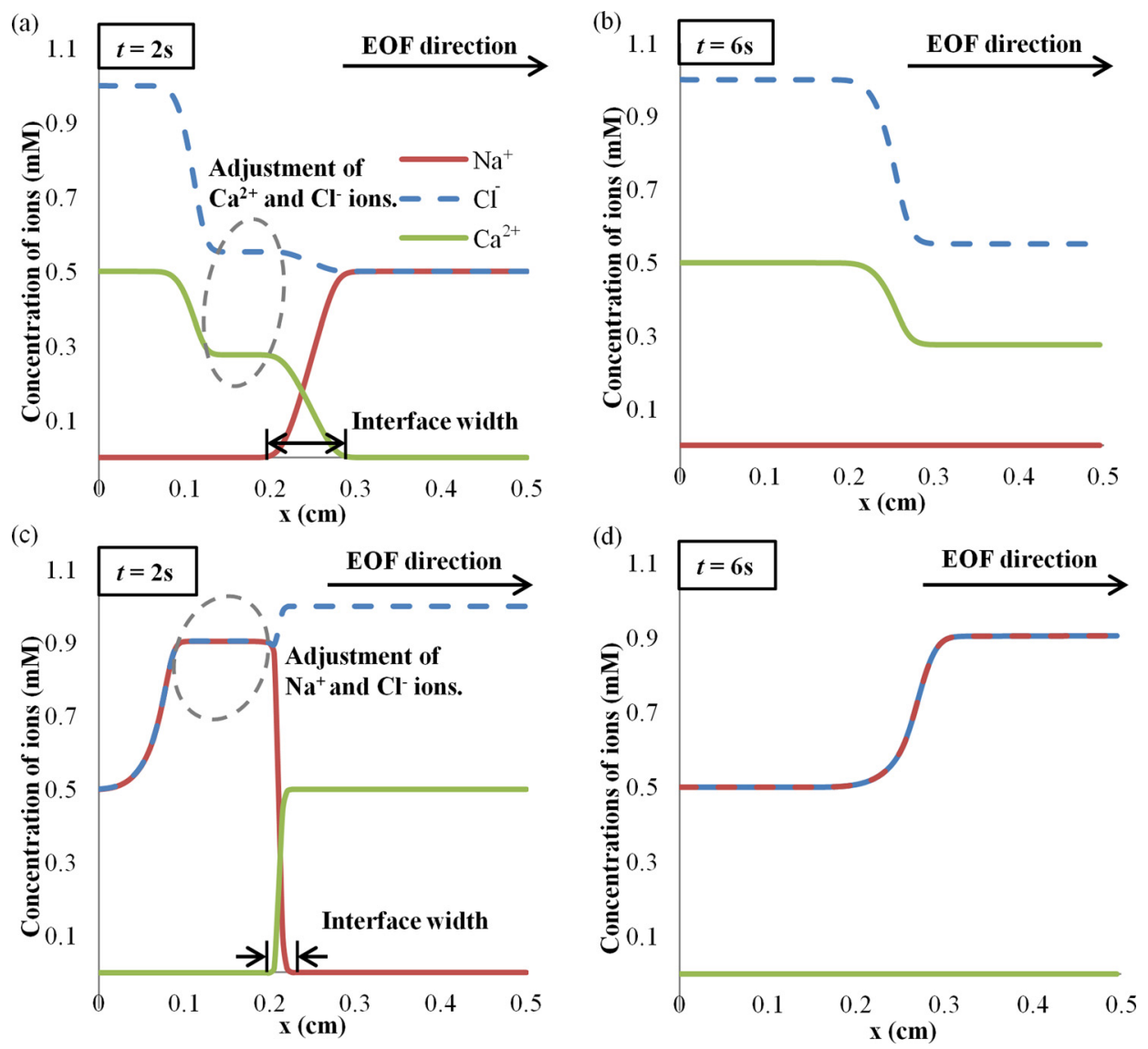

FIG. 12. Simulated ion concentrations at axis of symmetry along microchannel when (a) $0.5 \mathrm{mM} \mathrm{CaCl}_{2}$ displaces $0.5 \mathrm{mM}$ $\mathrm{NaCl}$ in Phase $1(t=2 \mathrm{~s})$ and (b) Phase $2(t=6 \mathrm{~s})$, and (c) $0.5 \mathrm{mM} \mathrm{NaCl}$ displaces $0.5 \mathrm{mM} \mathrm{CaCl}_{2}$ in Phase $1(t=2 \mathrm{~s})$ and (d) Phase $2(t=6 \mathrm{~s})$.
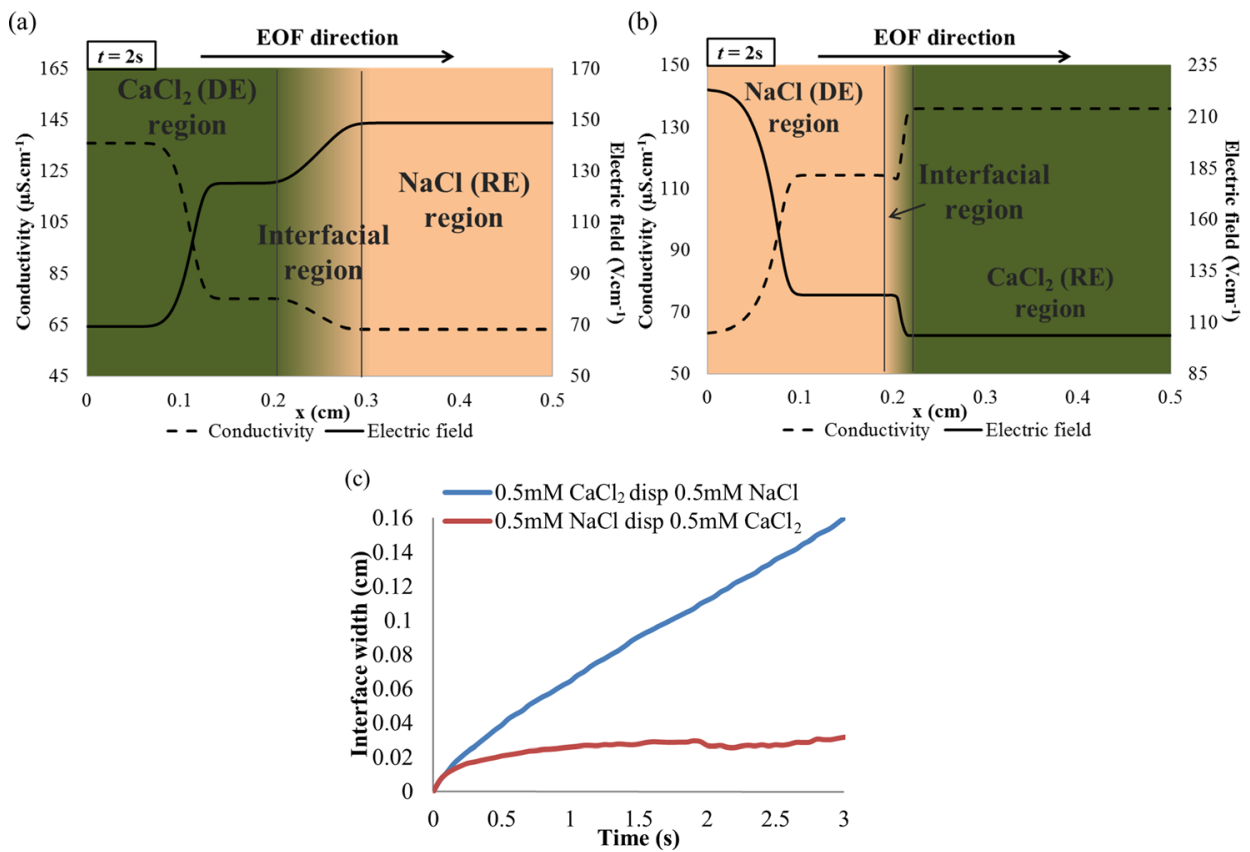

FIG. 13. Simulated conductivity and electric field at axis of symmetry along microchannel in Phase $1(t=2 \mathrm{~s})$ when (a) $0.5 \mathrm{mM}$ $\mathrm{CaCl}_{2}$ displaces $0.5 \mathrm{mM}$ and (b) $0.5 \mathrm{mM} \mathrm{NaCl}$ displaces $0.5 \mathrm{mM} \mathrm{CaCl}_{2}$. (c) Simulated interface widths in both flow directions. 

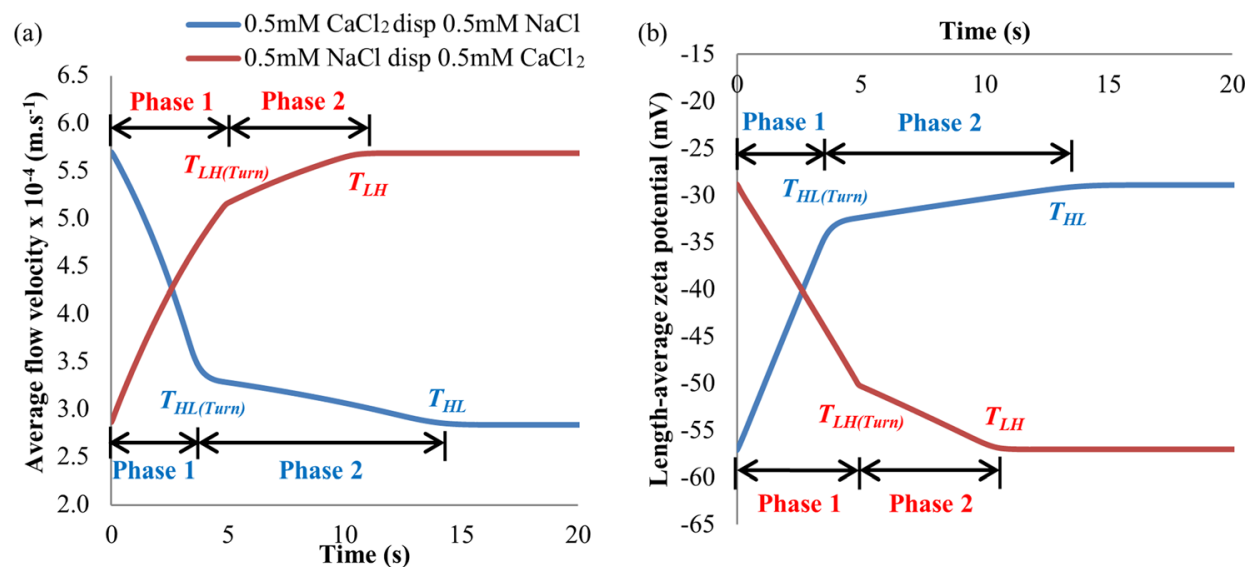

FIG. 14. Simulated (a) average flow velocity $u_{\text {ave }}$ and (b) length-average zeta potential $\bar{\zeta}$ for displacement flow of $0.5 \mathrm{mM}$ $\mathrm{CaCl}_{2}-\mathrm{NaCl}$ in both flow directions.

Similar to the case of $\mathrm{KCl}-\mathrm{NaCl}$ solution pair, subsequent current changes during Phase 2 are due to the displacement flow of DE at different concentrations which are produced in Phase 1 from the ion adjustment effect. Fig. 14(b) clearly shows that $\bar{\zeta}$ for $0.27 \mathrm{mM}-0.5 \mathrm{mM} \mathrm{CaCl}_{2}$ is at least $35 \%$ smaller than that for $0.5 \mathrm{mM}-0.9 \mathrm{mM} \mathrm{NaCl}$. Consequently, $u_{\text {ave }}$ for $0.5 \mathrm{mM}-0.9 \mathrm{mM} \mathrm{NaCl}$ is much faster than that for $0.27 \mathrm{mM}-0.5 \mathrm{mM} \mathrm{CaCl} 2$ (see Fig. 14(a)), which provides the explanation for $T_{H L}$ being longer than $T_{L H}$.

\section{CONCLUSION}

EOF involving solution pair with dissimilar ionic species was investigated both experimentally and numerically. Current monitoring experiments were carried out to monitor the displacement flow behaviors of different solution pairs through the current-time curves. Numerical simulations based on FEM were also performed to elucidate the movement of ions and flow behavior during the displacement process.

Two important times which exhibit hysteretic or flow direction-dependent behavior can be identified: turning time which marks the abrupt gradient change of current-time curve and displacement time which is the time for one solution to completely displace the initial solution (indicated by a steady current). The turning time divides the EOF displacement flow into two distinct phases: namely, Phase 1, where the residing (initial) electrolyte is displaced, and Phase 2 , which involves the concentration adjustment of the displacing electrolyte. Both simulation and experimental results demonstrate that the turning and displacement times for a particular solution pair can differ with the flow direction.

Two different mechanisms have been identified as the causes for the EOF hysteresis involving dissimilar ionic solutions. The first mechanics is the widening/sharpening effect of the interfacial region between the two solutions induced by conductivity difference between the two solutions. This effect is weak and is only significant if the average flow velocity difference (induced by other effects) between both directions is small, e.g., $\mathrm{NaCl}-\mathrm{KCl}$ solution pair.

The second mechanics involves the difference in length-averaged zeta potential in both flow directions. This effect is pronounced in the case whereby the zeta potentials of the two solutions differ significantly, e.g., $\mathrm{CaCl}_{2}-\mathrm{NaCl}$ solution pair. The ion concentration adjustments in the two different flow directions are indeed different as indicated by the simulations, and thus, the average zeta potentials are not the same when the flow is reversed.

\section{ACKNOWLEDGMENTS}

The authors would like to gratefully acknowledge Agency for Science, Technology and Research (A*STAR) for its financial support (SERC Grant No. 122-PSF-0019). A. E. Lim thanks Nanyang Technological University (NTU) for awarding him a Ph.D scholarship. 
${ }^{1}$ C. Y. Lim, Y. C. Lam, and C. Yang, Biomicrofluidics 4(1), 014101 (2010).

${ }^{2}$ H. Song, Z. Cai, H. Noh, and D. J. Bennett, Lab Chip 10(6), 734-740 (2010).

${ }^{3}$ S. Yao, D. E. Hertzog, S. Zeng, J. C. Mikkelsen, Jr., and J. G. Santiago, J. Colloid Interface Sci. 268(1), 143-153 (2003).

${ }^{4} \mathrm{M}$. Gao and L. Gui, Lab Chip 14(11), 1866-1872 (2014).

${ }^{5}$ T. Kawamata, M. Yamada, M. Yasuda, and M. Seki, Electrophoresis 29(7), 1423-1430 (2008).

${ }^{6} \mathrm{~J}$. Li, W. Ding, and J. S. Fritz, J. Chromatogr. A 879(2), 245-257 (2000).

${ }^{7}$ P. K. Wong, C. Y. Chen, T. H. Wang, and C. M. Ho, Anal. Chem. 76(23), 6908-6914 (2004).

${ }^{8}$ M. C. Morales, H. Lin, and J. D. Zahn, Lab Chip 12(1), 99-108 (2012).

${ }^{9}$ Y. Hua, A. B. Jemere, J. Dragoljic, and D. J. Harrison, Lab Chip 13(13), 2651-2659 (2013).

${ }^{10}$ B. C. Giordano, D. S. Burgi, S. J. Hart, and A. Terray, Anal. Chim. Acta 718, 11-24 (2012).

${ }^{11}$ A. Šlampová, Z. Malá, P. Pantůčková, P. Gebauer, and P. Boček, Electrophoresis 34(1), 3-18 (2013).

${ }^{12}$ H. C. Chang and L. Y. Yeo, Electrokinetically Driven Microfluidics and Nanofluidics (Cambridge University Press, New York, 2010).

${ }^{13}$ S. Devasenathipathy, R. Bharadwaj, and J. G. Santiago, Exp. Fluids 43(6), 959-967 (2007).

${ }^{14}$ X. Hou, D. Deng, X. Wu, Y. Lv, and J. Zhang, J. Chromatogr. A 1217(35), 5622-5627 (2010).

${ }^{15}$ S. Mallampati, K. Wolfs, M. M. Pendela, J. Hoogmartens, and A. V. Schepdael, J. Liq. Chromatogr. Relat. Technol. 33(6), 802-817 (2010).

${ }^{16}$ M. M. Hsieh, E. P. Lin, and S. W. Huang, Talanta 88(0), 638-645 (2012).

${ }^{17}$ J. M. Sustarich, B. D. Storey, and S. Pennathur, Phys. Fluids 22(11), 112003 (2010).

${ }^{18} \mathrm{X}$. Zhang and Z. Zhang, J. Pharm. Biomed. Anal. 56(2), 330-335 (2011).

${ }^{19}$ X. Huang, M. J. Gordon, and R. N. Zare, Anal. Chem. 60(17), 1837-1838 (1988).

${ }^{20}$ Z. A. Almutairi, T. Glawdel, C. L. Ren, and D. A. Johnson, Microfluid. Nanofluid. 6(2), 241-251 (2009).

${ }^{21}$ A. Sze, D. Erickson, L. Ren, and D. Li, J. Colloid Interface Sci. 261(2), 402-410 (2003).

${ }^{22}$ V. Tandon, S. K. Bhagavatula, and B. J. Kirby, Electrophoresis 30(15), 2656-2667 (2009).

${ }^{23}$ L. Ren, C. Escobedo, and D. Li, J. Colloid Interface Sci. 250(1), 238-242 (2002).

${ }^{24}$ S. W. Tang, C. H. Chang, and H. H. Wei, Microfluid. Nanofluid. 10(2), 337-353 (2011).

${ }^{25}$ L. Ren, J. Masliyah, and D. Li, J. Colloid Interface Sci. 257(1), 85-92 (2003).

${ }^{26}$ L. Ren, C. Escobedo, and D. Li, J. Colloid Interface Sci. 242(1), 264-271 (2001).

${ }^{27}$ D. Mampallil, D. v. d. Ende, and F. Mugele, Electrophoresis 31(3), 563-569 (2010).

${ }^{28}$ C. Y. Lim and Y. C. Lam, Biomicrofluidics 6(1), 012816 (2012).

${ }^{29}$ D. G. Yan, C. Yang, and X. Y. Huang, Microfluid. Nanofluid. 3(3), 333-340 (2007).

${ }^{30}$ I. Rodríguez and N. Chandrasekhar, Electrophoresis 26(6), 1114-1121 (2005).

${ }^{31}$ B. J. Kirby, Micro- and nanoscale Fluid Mechanics: Transport in Microfluidic Devices (Cambridge University Press, New York, 2010).

${ }^{32}$ G. Tang, D. Yan, C. Yang, H. Gong, J. C. Chai, and Y. C. Lam, Electrophoresis 27(3), 628-639 (2006).

${ }^{33}$ S. Arulanandam and D. Li, J. Colloid Interface Sci. 225(2), 421-428 (2000).

${ }^{34}$ K. Kim, H. S. Kwak, and T. H. Song, Fluid Dyn. Res. 43(4), 041401 (2011). 